\title{
IMPLEMENTASI KEBIJAKAN PENERIMAAN PESERTA DIDIK BARU BERDASARKAN SISTEM ZONASI DI KOTA BANDUNG
}

\section{IMPLEMENTATION OF NEW STUDENT ADMISSION POLICY BASED ON ZONING SYSTEM IN BANDUNG CITY}

\author{
Dian Purwanti ${ }^{*}$, Ira Irawati2 ${ }^{2}$ Jossy Adiwisastra ${ }^{3}$, Herijanto Bekti ${ }^{4}$ \\ 1Program Studi Administrasi Publik, Fakultas Ilmu Sosial dan Ilmu Politik, Universitas \\ Muhammadiyah Sukabumi, Jawa Barat, Indonesia \\ 2,3,4Fakultas Ilmu Sosial dan Ilmu Politik, Universitas Padjadjaran Bandung, Jawa Barat, \\ Indonesia \\ *Korespondensi: Dian Purwanti. Email: purwantidian75@yahoo.com
}

(Diterima: 15 Maret 2019; Ditelaah: 25 Maret 2019; Disetujui: 4 April 2019)

\begin{abstract}
The new student admission based on zoning system has been implemented in Indonesia since 2017 through the Ministerial Regulation of Education and Culture No. 17/2017, then renewed by the Ministerial Regulation of Education and Culture No. 18/2018. The regulation has been enacted for the Local Office of Education in all regencies/cities in Indonesia. To be implemented, every regency and city have enacted the operational regulations in accordance with each local conditions. The Local Government of Bandung City has implemented the zoning system since 2017, namely the Regulation of Mayor of Bandung No. 553/2017 and the Regulation of Mayor of Bandung No. 456/2018. The both regulations have the different rule of game, particularly the application of quota. The zoning quota of new student admission in 2017 was regulated only for 40-50 percent, but Bandung City in 2018 applied the zoning system for 100 percent. The aims of applying the zoning system were to closely bring the students to their residences, to reduce the costs of school transportation, and to eliminate the dichotomy between the favorite and unfavorite schools. The research uses the paired sample t-Test to compare the both Mayoral Regulations and to then find the dominant factor as the cause for occuring the conflict in the process of new student admission in Bandung City. Matland's ambiguityconflict model is used to explain the implementation of new student admission policy. Results of the research indicate that the dichotomy of favorite and unfavorite schools can not be removed, not just because of the public mindset, but also because of the unsupporting policy of local government, and the unreadiness of local government to provide the qualified infrastructures for the education in all schools.
\end{abstract}

Keywords: School Dichotomy, Policy Implementation, New Student Admission, Zoning System.

\section{ABSTRAK}

Penerimaan peserta didik baru sistem zonasi telah diberlakukan di Indonesia melalui Permendikbud No. 17/2017 jo. Permendikbud No. 18/2018. Kebijakan ini berlaku bagi seluruh Dinas Pendidikan kabupaten/ kota di Indonesia. Atas dasar ini, setiap daerah membuat kebijakan turunan sesuai dengan kondisi masingmasing. Pemerintah Kota Bandung telah menerapkan sistem zonasi melalui Perwal No. 553/2017 dan Perwal No. 456/2018. Kedua Perwal ini memiliki aturan main yang berbeda, terutama dalam hal penerapan kuota. Kuota zonasi pada penerimaan peserta didik baru tahun 2017 diatur hanya 40-50 persen, akan tetapi tahun 2018 menerapkan sistem zonasi 100 persen. Tujuan sistem zonasi adalah untuk mendekatkan peserta didik dengan domisili siswa, mengurangi biaya transportasi pendidikan, serta menghilangkan dikhotomi sekolah favorit dan tidak favorit. Penelitian ini menggunakan Paired Sample t-Test untuk membandingkan kedua Perwal dan kemudian menemukan faktor paling dominan sebagai penyebab timbulnya konflik pada proses penerimaan peserta didik baru di Kota Bandung. Ambiguity-conflict model Matland (1995) digunakan untuk menjelaskan implementasi kebijakan penerimaan peserta didik baru. Hasil penelitian menunjukkan bahwa dikhotomi sekolah favorit dan tidak favorit belum dapat dihilangkan bukan semata karena pola fikir masyarakat, melainkan juga karena kebijakan pemerintah daerah yang tidak mendukung, serta ketidaksiapan pemerintah daerah dalam menyediakan sarana dan prasarana pendidikan yang berkualitas di semua sekolah.

Kata Kunci: Dikhotomi Sekolah, Implementasi Kebijakan, Penerimaan Peserta Didik Baru, Sistem Zonasi.

Dian Purwanti. 2019. Implementasi Kebijakan Penerimaan Peserta Didik Baru berdasarkan Sistem Zonasi di Kota Bandung. 


\section{PENDAHULUAN}

Penerimaan Peserta Didik Baru adalah penerimaan peserta didik untuk jenjang taman kanak-kanak, sekolah dasar dan sekolah menengah pertama yang dilaksanakan pada awal tahun pelajaran baru. PPDB jenjang SMP dilakukan secara online, prioritasnya adalah anak usia 12-15 tahun (Permendikbud No. 17 Tahun 2017). Seleksi dilakukan melalui sistem zonasi. Penerimaan peserta didik baru Kota Bandung mengusung asas objektif, transparan, akuntabel, dan berkeadilan (Perwal No. 456 Tahun 2018).

Dalam implementasinya sejak tahun ajaran 2017/2018, Kota Bandung telah menerapkan sistem zonasi, yaitu sistem penerimaan peserta didik baru berdasarkan radius dan jarak, meskipun belum seratus persen. Melalui sistem zonasi ini diharapkan semua warga Kota Bandung bisa mendapatkan pendidikan yang lokasinya dekat dengan tempat tinggal. Menurut Dinas Pendidikan Kota Bandung, kelebihan sistem zonasi ini adalah pemerataan pendidikan, lebih hemat waktu karena sekolah dekat, lebih hemat biaya transportasi, kondisi peserta didik lebih bugar, serta mengurangi kemacetan. Namun dalam implementasinya kebijakan PPDB di Kota Bandung selalu menuai konflik.

Dalam penelitian ini, peneliti menggunakan referensi dari jurnal penelitian terkait PPDB di berbagai kota di Indonesia yang pernah dilakukan, data sekunder dari pihak Dinas Pendidikan Kota Bandung, serta data primer yang diperoleh langsung dari para narasumber yang peneliti wawancarai, maupun angket yang disebar kepada panitia penyelenggara penerimaan peserta didik baru tingkat sekolah. Adapun proses analisisnya menggunakan uji dua vektor rata-rata dari Wichern berdasarkan sampel dependent.

\section{MATERI DAN METODE}

\section{Konsep/Teori yang Relevan}

Beberapa teori terkait implementasi kebijakan dikemukakan oleh para ahli, di antaranya, Paul A. Sabatier dan Daniel A. Mazmanian mengemukakan: Implementation is the carrying out a basic policy decision, usually incorporated in a statute but which can also take the form of important executive or court decisions. Ideally that the decision identitas the problems (s) to be addressed, stipulates the objective (s) to be pursued and in a variety of ways, structures the implementation process (1983: 20).

Sabatier dan Mazmanian menegaskan bahwa implementasi kebijakan berarti mewujudkan suatu keputusan kebijakan yang memiliki legalitas hukum - dapat berbentuk undang-undang, peraturan pemerintah, keputusan eksekutif, dan lainlain dalam bentuk program-program kerja yang merujuk pada masalah yang akan ditangani oleh kebijakan.

Selain itu sebagai bagian dari proses kebijakan, maka dari hasil implementasilah kebijakan memperoleh umpan balik, apakah perlu kebijakan direvisi atau tidak sebagaimana yang dikatakan oleh Sabatier dan Mazmanian: The process normally runs through a number of stages beginning with passage the basic statute, followed by policy outputs (decisions) of the implementing agencies, the compliance of target groups with those outputs, the perceived impacts of agency decisions, an finally important revisions (or attempted revisions) in the basic statute (1983: 20).

Dari model sistem tersebut, fungsi implementasi adalah mentransformasikan tujuan kebijakan ke dalam bentuk-bentuk kegiatan operasional yang dibutuhkan agar kebijakan mencapai tujuannya. Fungsi implementasi tidak akan berubah, sekalipun kebijakan yang diimplementasikan berbeda, yang berbeda adalah hasil akhirnya. Sedangkan tujuan implementasi itu sendiri adalah menghasilkan perubahan sebagaimana yang dikehendaki oleh kebijakan. Oleh karenanya jika dikatakan bahwa sebuah kebijakan dibuat untuk mengintervensi peri kehidupan publik, maka implementasi adalah bentuk nyata dari tindakan intervensi itu sendiri. 
Pressmann dan Wildavsky (1984: xivxv) menyatakan bahwa policy implementation adalah menjalankan program kerja yang disusun setelah hipotesis permasalahan ditemukan dan diterjemahkan ke dalam bentuk-bentuk tindakan yang telah disahkan, atau jelasnya sebagai berikut:

A program consists of governmental action initiated in order to secure objectives whose attainment is problematic. A program exists when the initial conditions - the "if" stage of the policy hypothesis - have been met. The word "program" signifies the conversion of a hypothesis in to governmental action. The initial premises of the hypothesis have been authorized. The degree to which predicated consequences (the "then" stage) take place we will call implementation.

Sebagai tindakan intervensi, maka faktor kritis dalam proses implementasi adalah merancang struktur implementasinya, yakni memilih tindakan-tindakan operasional yang tepat, serta mengoperasionalkan tindakan-tindakan tersebut secara tepat pula ke dalam bentuk program dan proyek.

Sementara itu Richard E. Matland (1995) mengembangkan Model Matriks Ambiguitas-Konflik untuk menjelaskan bahwa implementasi secara admiministratif adalah implementasi yang dilakukan dalam keseharian operasi birokrasi pemerintahan. Kebijakan di sini memiliki ambiguitas atau kemenduaan yang rendah dan konflik yang rendah. Implementasi secara politik adalah implementasi yang perlu dipaksakan secara politik, karena walaupun ambiguitasnya rendah, tingkat konfliknya tinggi. Implementasi secara eksperimen dilakukan pada kebijakan yang mendua, namun tingkat konfilknya rendah. Implementasi secara simbolik dilakukan pada kebijakan yang mempunyai ambiguitas tinggi dan konflik yang tinggi. Pemikiran Matland dikembangkan lebih rinci sebagai berikut:
Tabel 1. Matriks Ambiguitas-Konflik Matland

\begin{tabular}{|l|l|l|}
\hline \multirow{4}{*}{$\begin{array}{l}\text { Low } \\
\text { Ambiguity }\end{array}$} & $\begin{array}{l}\text { Low Conflict } \\
\text { Implementation }\end{array}$ & \multicolumn{1}{|c|}{ High Conflict } \\
\cline { 2 - 3 } & $\begin{array}{l}\text { Implementation } \\
\text { implementation } \\
\text { decided by } \\
\text { recources }\end{array}$ & $\begin{array}{l}\text { Implementation } \\
\text { decided by } \\
\text { power }\end{array}$ \\
\cline { 2 - 3 } & $\begin{array}{l}\text { Example: } \\
\text { smallpox } \\
\text { eradication }\end{array}$ & Example: busing \\
\hline High & $\begin{array}{l}\text { Experimental } \\
\text { implementation }\end{array}$ & $\begin{array}{l}\text { Symbolyc } \\
\text { implementation }\end{array}$ \\
\cline { 2 - 3 } & $\begin{array}{l}\text { Implementation } \\
\text { decided by } \\
\text { contextual } \\
\text { conditions }\end{array}$ & $\begin{array}{l}\text { Implementation } \\
\text { s decided by } \\
\text { coalition } \\
\text { strength }\end{array}$ \\
\cline { 2 - 3 } & $\begin{array}{l}\text { Example: } \\
\text { headstart }\end{array}$ & $\begin{array}{l}\text { Example: } \\
\text { community } \\
\text { action agencies }\end{array}$ \\
\hline
\end{tabular}

Sumber: Richard E. Matland, 1995

Pada prinsipnya matriks Matland memiliki "empat tepat" yang perlu dipenuhi dalam hal keefektifan implementasi kebijakan, yaitu:

Pertama: Ketepatan Kebijakan. Ketepatan kebijakan dinilai dari tiga hal, yaitu:

1. Sejauh mana kebijakan yang ada telah bermuatan hal-hal yang memang memecahkan masalah yang hendak dipecahkan. Pertanyaannya adalah how excelent is the policy.

2. Apakah kebijakan tersebut sudah dirumuskan sesuai dengan karakter masalah yang hendak dipecahkan.

3. Apakah kebijakan dibuat oleh lembaga yang mempunyai kewenangan (misi kelembagaan) yang sesuai dengan karakter kebijakan.

Kedua: Ketepatan Pelaksana. Aktor implementasi kebijakan tidaklah hanya pemerintah. Ada tiga lembaga yang bisa menjadi pelaksana, yaitu:

1. Pemerintah. Kebijakan-kebijakan yang bersifat monopoli, seperti kartu identitas penduduk, atau mempunyai derajad 
politik keamanan yang tinggi, seperti pertahanan dan keamanan, sebaiknya diselenggarakan oleh pemerintah.

2. Kerjasama antara pemerintah-masyarakat/swasta. Kebijakan yang bersifat memberdayakan masyarakat, seperti penanggulangan kemiskinan, sebaiknya diselenggarakan pemerintah bersama masyarakat/swasta.

3. Implementasi kebijakan yang diswastakan (privatization atau contracting out). Kebijakan yang bertujuan mengarahkan kegiatan-kegiatan masyarakat, seperti bagaimana perusahaan harus dikelola, atau dimana pemerintah tidak efektif menyelenggarakannya sendiri, seperti pembangunan industri-industri berskala menengah dan kecil yang tidak strategis, sebaiknya diserahkan kepada masyarakat.

Ketiga: Ketepatan Sasaran. Ketepatan sasaran (target) berkenaan dengan tiga hal, yaitu:

1. Apakah target yang diintervensi sesuai dengan yang direncanakan, apakah tidak ada tumpang tindih dengan intervensi lain, atau tidak bertentangan dengan intervensi kebijakan lain.

2. Apakah targetnya dalam kondisi siap untuk diintervensi ataukah tidak. Kesiapan bukan saja dalam arti secara alami, namun juga apakah kondisi target ada dalam konflik atau harmoni, dan apakah kondisi target ada dalam kondisi mendukung atau menolak.

3. Apakah intervensi implementasi kebijakan bersifat baru atau memperbarui implementasi kebijakan sebelumnya. Terlalu banyak kebijakan yang tampaknya baru namun pada prinsipnya mengulang kebijakan yang lama dengan hasil yang sama tidak efektifnya dengan kebijakan sebelumnya.

Keempat: Ketepatan Lingkungan. Ada dua lingkungan yang paling menentukan, yaitu:

1. Lingkungan Kebijakan. Lingkungan kebijakan menyangkut interaksi antara lembaga perumus kebijakan dengan pelaksana kebijakan dan dengan lembaga yang terkait. Donald J. Calista menyebutnya sebagai variabel endogen, yaitu authoritative arrangement yang berkenaan dengan kekuatan sumber otoritas dari kebijakan, network composition yang berkenaan dengan komposisi jejaring dari berbagai organisasi yang terlibat kebijakan, baik dari pemerintah maupun masyarakat, implementation setting yang berkenaan dengan posisi tawar-menawar antara otoritas yang mengeluarkan kebijakan dan jejaring yang berkenaan dengan implementasi kebijakan.

2. Lingkungan Eksternal Kebijakan. Lingkungan ini oleh Calista disebut sebagai variabel eksogen, yang terdiri dari public opinion, yaitu persepsi publik akan kebijakan dan implementasi kebijakan, interpretive institutions yang berkenaan dengan interprestasi lembaga-lembaga strategis dalam masyarakat, seperti media massa, kelompok penekan, dan kelompok kepentingan, dalam menginterpretasikan kebijakan dan implementasi kebijakan, dan individuals, yakni individu-individu tertentu yang mampu memainkan peran penting dalam menginterpretasikan kebijakan dan implementasi kebijakan.

Ke-empat "tepat" tersebut masih perlu didukung oleh tiga jenis dukungan, yaitu:

1. Dukungan politik;

2. Dukungan strategik; dan

3. Dukungan teknis.

Selain tiga dukungan di atas, penelitian ataupun analisis tentang implementasi kebijakan sebaiknya juga menggunakan model implementasi sesuai dengan isu kebijakannya, sebagaimana yang digambarkan oleh Matland sebagai berikut: 
Gambar 1. Model Ambiguitas-Konflik Matland

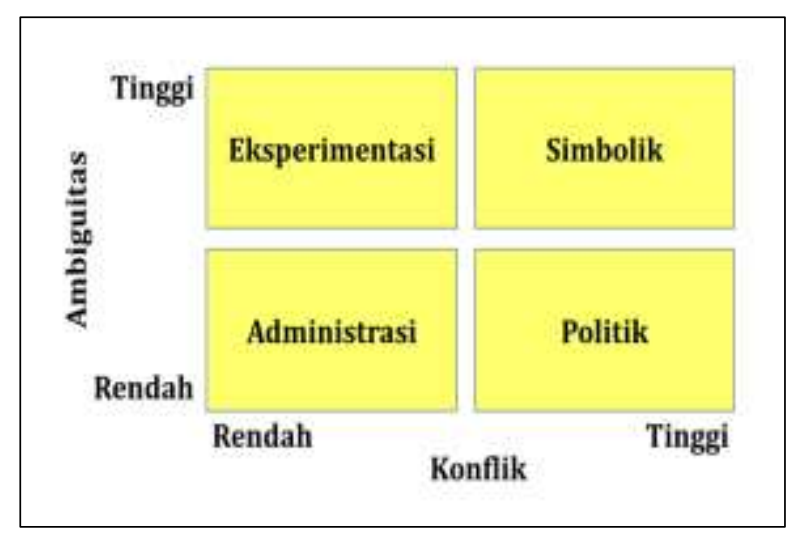

Sumber: Richard E. Matland, 1995

Adapun kriteria atau ukuran mengenai pencapaian tujuan efektif atau tidak, sebagaimana dikemukakan oleh Siagian (1978: 77) sebagai berikut:

a. Kejelasan tujuan yang hendak dicapai. Hal ini dimaksudkan agar panitia PPDB dalam melaksanakan tugas mencapai sasaran yang terarah dan tujuan Dinas Pendidikan menerapkan sistem zonasi dapat tercapai.

b. Kejelasan strategi pencapaian tujuan. Telah diketahui bahwa strategi adalah on the track yang diikuti dalam melakukan berbagai upaya dalam mencapai sasaransasaran yang ditentukan agar para implementor tidak tersesat dalam pencapaian tujuan kebijakan sistem zonasi.

c. Proses analisis dan perumusan kebijakan yang mantap. Hal ini berkaitan dengan tujuan yang hendak dicapai dan strategi yang telah ditetapkan artinya kebijakan harus mampu menjembatani tujuantujuan dengan usaha-usaha pelaksanaan kegiatan operasional.

d. Perencanaan yang matang. Hal ini pada hakekatnya berarti memutuskan sekarang apa yang harus dikerjakan oleh Dinas Pendidikan di masa depan.

e. Penyusunan program yang tepat. Suatu rencana yang baik masih perlu dijabarkan ke dalam program-program pelaksanaan yang tepat sebab apabila tidak, para pelaksana akan kurang memiliki pedoman bertindak dan bekerja.

f. Tersedianya sarana dan prasarana kerja. Salah satu indikator efektivitas organisasi adalah kemampuan bekerja secara produktif, dengan sarana dan prasarana yang tersedia dan mungkin disediakan oleh Dinas Pendidikan.

g. Pelaksanaan yang efektif dan efisien. Bagaimanapun baiknya kebijakan sistem zonasi apabila tidak diimplementasikan secara efektif dan efisien maka Dinas Pendidikan tidak akan mencapai sasarannya, karena melalui implementasi kebijakan, organisasi semakin didekatkan pada tujuannya.

h. Sistem pengawasan dan pengendalian yang bersifat mendidik. Mengingat sifat manusia yang tidak sempurna maka efektivitas organisasi menuntut terdapatnya sistem pengawasan dan pengendalian. Begitu pula dalam proses implementasi kebijakan sistem zonasi.

\section{Hipotesis Penelitian}

Adapun hipotesis penelitian dapat dirumuskan sebagai berikut:

Kebijakan Penerimaan Peserta Didik Baru Sistem Zonasi efektif jika memenuhi syarat ketepatan kebijakan, ketepatan pelaksana, ketepatan sasaran, dan ketepatan lingkungan.

\section{Metode Penelitian}

Uji beda rata-rata dikenal juga dengan nama uji-t (t-test). Konsep dari uji beda rata-rata adalah membandingkan nilai ratarata beserta selang kepercayaan tertentu (confidence interval) dari dua populasi. Prinsip pengujian dua rata-rata adalah melihat perbedaan variasi kedua kelompok data. Oleh karenanya diperlukan informasi apakah varian kedua kelompok yang diuji sama atau tidak Dependent Sample t-Test atau sering diistilahkan dengan Paired Sample t-Test, adalah jenis uji statistika yang bertujuan untuk membandingkan rata-rata dua kelompok yang saling berpasangan. 
Sampel berpasangan dapat diartikan sebagai sebuah sampel dengan subjek yang sama namun mengalami dua perlakuan atau pengukuran yang berbeda, yaitu pengukuran sebelum dan sesudah dilakukan sebuah perlakuan (treatment).

Dalam penelitian ini, indikatorindikator dari dimensi-dimensi tidak merupakan indikator reflektif melainkan merupakan indikator formatif, sehingga untuk mengevaluasi kualitas pengukuran tidak menggunakan uji validitas dan reliabilitas secara tradisional. Karenanya dalam penelitian ini, kualitas pengukuran dievaluasi melalui Analisis Komponen Utama (Johnson \& Wichern, 2007). Dalam hal ini, ukuran-ukuran statistik yang dipergunakan untuk mengevaluasi model pengukuran formatif adalah relevansi indikator (Hair dkk., 2014: 132). Relevansi indikator formatif dilihat dari signifikansi koefisien bobot komponen utama. Koefisien bobot yang signifikan menunjukkan dimensi tersebut relevan. Pengujian mengikuti prosedur pengujian koefisien bobot komponen utama di dalam Johnson dan Wichern (2007).

\section{Pengujian Hipotesis}

Pengujian hipotesis dalam penelitian ini menggunakan statistik uji:

$F=\frac{(n-p) n}{(n-1) p} \overline{\mathbf{d}}^{\prime} \mathbf{S}_{\mathbf{d}}^{-1} \overline{\mathbf{d}} \sim F_{(p, n-p)}$.

jika hasil uji rata-rata semua vector signifikan dilanjutkan dengan uji vector menggunakan rumus Statistik uji sebagai berikut:

$$
t_{j}=\frac{\bar{d}_{j}}{\sqrt{\frac{s_{j}^{2}}{n}}} \sim t_{n-1} .
$$

Kriteria uji pada taraf signifikansi $\alpha$ : "tolak $H_{0}$ jika nilai $-p=2 P\left(t_{n-1} \geq|t|\right) \leq \frac{\alpha}{p}$ ”

\section{HASIL DAN PEMBAHASAN}

Kebijakan zonasi adalah sistem penerimaan peserta didik berdasarkan radius dan jarak. Melalui sistem zonasi diharapkan semua warga Kota Bandung bisa mendapatkan pendidikan yang lokasinya dekat dengan tempat tinggal. Kelebihan dari sistem zonasi di antaranya adalah pemerataan pendidikan, lebih hemat waktu karena sekolah dekat, lebih hemat biaya transportasi, kondisi peserta didik lebih bugar, serta mengurangi kemacetan.

Jika pada proses penerimaan peserta didik baru tahun 2017, penerapan kuota zonasi hanya 40 sampai dengan 50\% persen, maka pada tahun 2018 Dinas Pendidikan Kota Bandung memberlakukan kuota zonasi hingga $90 \%$ sesuai dengan tuntutan Permendikbud. Jika pada tahun 2017 masih terlihat perbedaan antara sekolah favorit dan tidak favorit, maka pada proses implementasi kebijakan tahun 2018 Dinas Pendidikan Kota Bandung melakukan pengelompokan sekolah menjadi tiga kelompok, yaitu:

1. Pertama: Kelompok A untuk sekolah yang berlokasi di dalam kota, di tengah pemukiman warga, dikenai aturan zonasi 90\% termasuk calon siswa dari kalangan RMP (rawan melanjutkan pendidikan) yang sebelumnya dikenal dengan istilah siswa miskin. Kelompok A terdiri dari 36 sekolah.

2. Kedua: Kelompok B untuk sekolah yang berlokasi di dalam kota namun jauh dari pemukiman warga karena berada di kawasan perkantoran. Untuk sekolah di kelompok B ini dikenai aturan zonasi bertahap, yaitu $50 \%$ zonasi dan $40 \%$ akademik. Ada 5 sekolah yang masuk ke dalam Kelompok B.

3. Ketiga: Kelompok C untuk sekolah yang lokasinya berbatasan dengan wilayah kabupaten. Untuk Kelompok C ini dikenai aturan zonasi perbatasan, yaitu $80 \%$ berasal dari dalam daerah Kota Bandung dan $10 \%$ dari luar daerah Kota Bandung. Terdapat 16 sekolah yang masuk ke dalam Kelompok C. 
Jika dianalisis dari segi ketepatan kebijakan, pada proses implementasi kebijakan penerimaan peserta didik baru sistem zonasi di Kota Bandung, proses formulasi kebijakan tidak mempertimbangkan pemetaan wilayah padat penduduk dan tidak padat penduduk usia sekolah, serta tidak ada standarisasi pendidikan di semua sekolah yang mengarah pada upaya menghilangkan dikhotomi sekolah favorit dan tidak favorit.

Jika dianalisis dari segi ketepatan pelaksana, dalam proses implementasi kebijakan penerimaan peserta didik baru zonasi di Kota Bandung, penerbitan kartu keluarga yang menjadi dasar penentuan radius domisili calon peserta didik baru hanya bisa dilakukan oleh Dinas Kependudukan dan Catatan Sipil, namun upaya pemalsuan data yang dilakukan oleh orang tua siswa dengan cara memasukkan nama calon peserta didik ke dalam kartu kelurga orang lain yang domisilinya dekat dengan sekolah yang dituju, luput dari pengawasan dan tidak ada proses verifikasi ke lapangan oleh Panitia Penerimaan Peserta Didik Baru, meskipun dalam struktur organisasi kepanitiaan terdapat bidang verifikasi.

Jika dianalisis dari segi ketepatan sasaran, pada proses penerimaan peserta didik baru zonasi tingkat SMP di Kota Bandung, target yang akan diintervensi tidak jelas, apakah calon peserta didik dari kalangan rawan melanjutkan pendidikan atau anak-anak pejabat dan aparat agar tetap bisa masuk ke SMP negeri favorit. Karena menurut data yang ada pada Dinas Pendidikan Kota Bandung, kuota RMP di sekolah favorit tidak terpenuhi meskipun sudah disediakan, karena tidak ada anakanak RMP yang mendaftar ke sekolah favorit, sehingga membuka peluang untuk melakukan praktek jual-beli kursi.

Jika dianalisis dari segi ketepatan lingkungan, pada proses implementasi kebijakan penerimaan peserta didik baru sistem zonasi tingkat SMP di Kota Bandung kurang interaksi antara perumus kebijakan dengan implementor tingkat bawah, sehingga banyak terjadi ketidaksesuaian antara aturan yang tertuang dalam kebijakan dengan implementasi di lapangan setelah melalui proses intervensi berupa memo oleh oknum yang berwenang atas kebijakan penerimaan peserta didik baru sistem zonasi di Kota Bandung. Kurangnya sosialisasi kebijakan kepada implementor kebijakan membuat implementor dan masyarakat kebingungan saat kebijakan diimplementasikan akibat tidak ada kesatupaduan antara perumus kebijakan dengan implementor kebijakan. Hal ini membuat wibawa implementor kebijakan turun di mata masyarakat.

Dinas Pendidikan Kota Bandung pada implementasi kebijakan PPDB sistem zonasi tahun ajaran 2018/2019 membagi SMP Negeri ke dalam tiga kelompok, dimana Kelompok A terdiri dari sekolah-sekolah yang dikenai aturan 90\% zonasi termasuk siswa Rawan Melanjutkan Pendidikan (RMP). Kelompok B terdiri dari lima sekolah favorit yang berada di kawasan perkantoran dan dikenai aturan zonasi bertahap, yaitu $50 \%$ zonasi $40 \%$ akademik. Selanjutnya Kelompok C adalah sekolah yang letaknya di perbatasan kota sehingga dikenai aturan zonasi perbatasan, dimana $80 \%$ siswa berasal dari dalam daerah, 10\% dari luar daerah. Berikut ini gambar datanya:

Gambar 2. Persentase Kuota PPDB SMP, Tahun 2018.

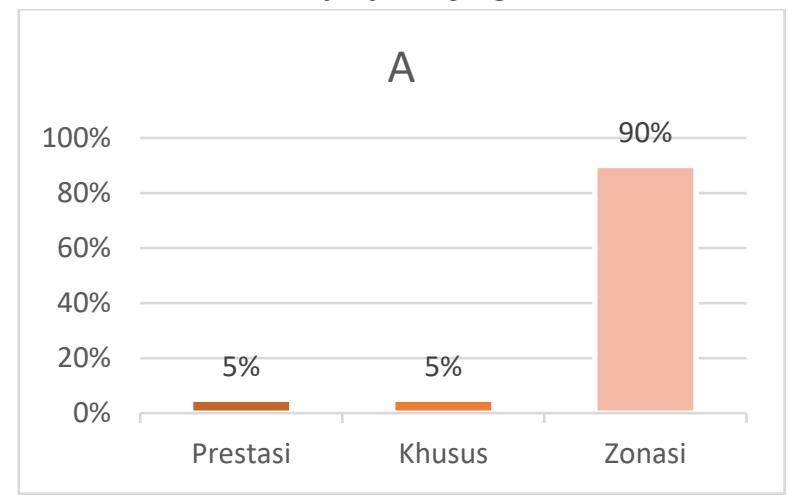


B
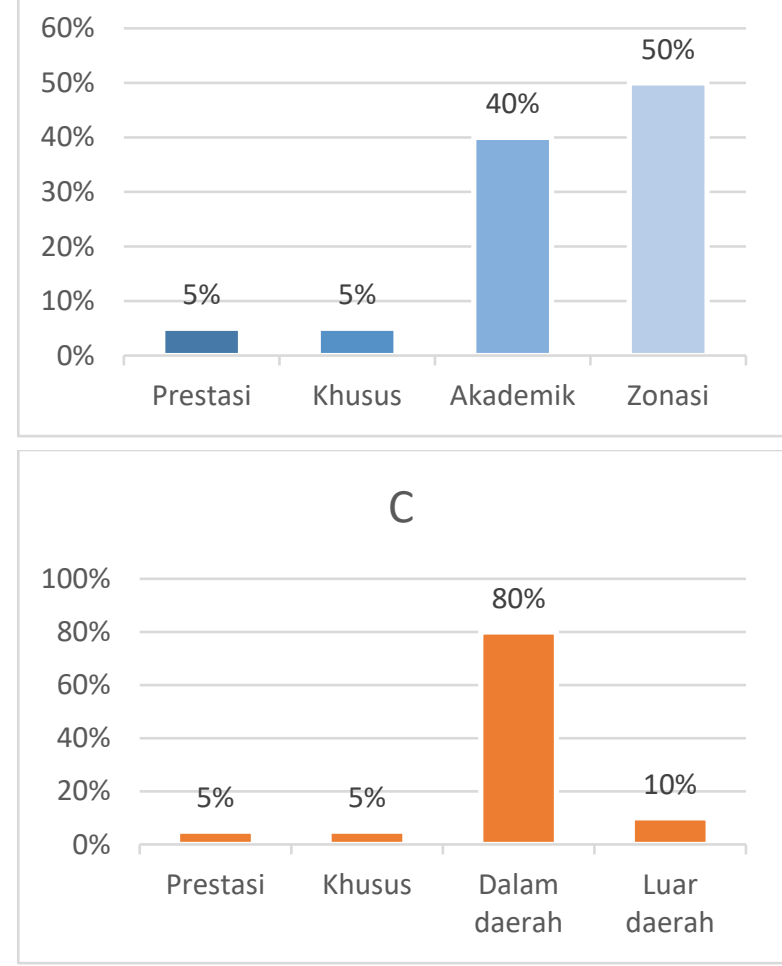

Sumber: hasil penelitian, 2018

Berdasarkan gambar di atas dapat dilihat bahwa untuk Dimensi Ketepatan Sasaran terdapat empat indikator yang menunjukkan peningkatan pada implementasi kebijakan tahun 2018 meskipun nilainya tidak signifikan.

Pertama: Indikator Dukungan Agen Pelaksana. Hal ini terkonfirmasi saat penelitian bahwa sudah menjadi sifat birokrat patuh dan taat pada pimpinan. Karenanya walaupun hati nurani para pelaksana (Panitia PPDB) menyatakan penolakan, dalam implementasinya Panitia PPDB tetap melaksanakan apa yang menjadi keputusan Dinas Pendidikan selaku organisasi induknya.

Kedua: Indikator selanjutnya adalah Kesesuaian Tindakan, sebagaimana telah dijelaskan pada indikator pertama Panitia PPDB yang menjadi pelaksana di tingkat sekolah selalu berusaha melakukan tindakan sesuai dengan kebijakan yang telah ditetapkan karena adanya pengawasan dari Dinas Pendidikan.
Ketiga: Pada indikator Meningkatnya APK RMP, terkonfirmasi saat penelitian lapangan bahwa dengan sistem zonasi murni otomatis seleksi kemampuan akademik calon siswa tergeser oleh zona. Dibukanya kran radius tempat tinggal terdekat ke sekolah membuat siswa yang domisilinya di sekitar sekolah dapat masuk tanpa seleksi akademik ke sekolah terdekat. Sisi positifnya adalah bahwa anak-anak yang rawan melanjutkan pendidikan namun domisilinya dekat dengan sekolah otomatis dapat diterima di sekolah terdekat, sehingga dalam tanda kutip Angka Partisipasi Kasar (APK) dari siswa Rawan Melanjutkan Pendidikan (RMP) meningkat. Mengapa tanda kutip ? karena belum ada data yang pasti mengenai kebenaran siswa RMP 100\% melanjutkan sekolah, faktanya surat keterangan miskin masih bisa dibuat oleh masyarakat yang mampu secara ekonomi bahkan orang tua siswa yang memiliki jabatan dan kewenangan untuk menekan aparat demi meluluskan keinginan putraputrinya masuk ke sekolah favorit tanpa tes, tidak sedikit masyarakat yang "cerdas" dan dekat pada penguasa melakukan tindakan curang dengan menitipkan putra-putrinya kepada famili yang domisilinya dekat sekolah.

Keempat: Selanjutnya untuk indikator Mendekatkan Sekolah Dengan Domisili Siswa, sudah pasti mengalami peningkatan, karena pada sistem zonasi murni kali ini $90 \%$ siswa yang diterima adalah siswa yang domisilinya dekat dengan sekolah. Kriteria utama kedekatan domisili dengan sekolah inilah yang menjadi pertentangan di kalangan masyarakat maupun panitia pelaksana. Karena dengan kriteria ini prestasi akademik siswa menjadi kurang dihargai, akhirnya masyarakat berfikir tidak perlu giat belajar untuk masuk ke sekolah favorit, cukup mengontrak rumah di dekat sekolah agar dapat diterima di sekolah favorit.

Selain keempat indikator yang mengalami peningkatan, hasil penelitian menunjukkan adanya dua indikator yang mengalami penurunan, yaitu indikator 
mengubah persepsi sekolah favorit dan menurunkan angka tidak melanjutkan sekolah. Data hasil penelitian menunjukkan adanya penurunan nilai, yang maknanya bahwa implementasi kebijakan sistem zonasi tahun 2018 belum mampu merubah persepsi masyarakat terhadap keberadaan sekolah favorit meskipun menurut Humas Dinas Pendidikan Kota Bandung semua sekolah sudah sesuai standar nasional namun dalam kenyataannya tingkat kepercayaan masyarakat terhadap kualitas sekolah masih belum berubah. Keinginan Dinas Pendidikan Kota Bandung mengubah persepsi masyarakat terhadap keberadaan sekolah favorit ternyata tidak didukung oleh kebijakan yang dibuatnya. Setidaknya hal ini terkonfirmasi saat peneliti melakukan penelitian lapangan, ironinya sistem PPDB Kota Bandung tahun 2018 justru secara tegas mengelompokkan sekolah ke dalam 3 Kelompok A, B, C, dimana kelompok $B$ dihuni oleh sekolahsekolah yang difavoritkan oleh masyarakat dengan sistem seleksi yang berbeda dengan sistem seleksi yang digunakan untuk sekolah yang ada di Kelompok A dan C. Kebijakan sistem zonasi tahun 2018 ternyata tidak menjamin menurunnya angka tidak melanjutkan sekolah. Hal ini terkonfirmasi saat peneliti melakukan wawancara kepada Panitia PPDB dan warga Kota Bandung yang menyatakan bahwa sistem zonasi tahun 2018 mengakibatkan anak-anak yang kurang mampu secara ekonomi namun unggul dalam prestasi tidak dapat diterima di SMP Negeri manapun karena radius tempat tinggalnya jauh dari lokasi sekolah, sementara kuota sekolah terdekat sudah penuh terisi.

\section{KESIMPULAN DAN REKOMENDASI}

\section{Kesimpulan}

Hasil penelitian tentang kebijakan sistem zonasi yang diimplementasikan pada tahun 2017 dan tahun 2018 menunjukkan bahwa implementasi kebijakan penerimaan peserta didik sistem zonasi tahun 2018 jika diukur dari indikator dukungan agen pelaksana, kesesuaian tindakan, meningkatnya APK RMP, dan mendekatkan sekolah dengan domisili siswa lebih baik dibandingkan dengan implementasi kebijakan sistem zonasi tahun 2017. Namun tidak efektif jika diukur dari indikator mengubah persepsi masyarakat terhadap sekolah favorit dan menurunkan angka tidak melanjutkan sekolah.

Terlepas dari dampak negatif yang ditimbulkan, harus diakui bahwa jika ditinjau dari segi ketepatan sasaran, implementasi kebijakan sistem zonasi pada tahun 2018 lebih baik jika dibandingkan dengan implementasi kebijakan pada tahun ajaran 2017. Artinya, walaupun tidak signifikan harus diakui ada upaya dari Pemerintah Kota Bandung untuk memperbaiki kebijakan sebelumnya, walaupun hasilnya tidak sesuai harapan.

\section{Rekomendasi}

Berdasarkan hasil penelitian yang dilakukan secara komparatif terhadap kebijakan sistem zonasi yang diimplementasikan pada tahun 2017 dan tahun 2018, peneliti memberikan rekomendasi sebagai berikut:

Pertama: Untuk menghilangkan dikhotomi sekolah favorit dan tidak favorit, Pemerintah Kota Bandung harus memperbaiki kualitas seluruh sekolah negeri yang ada di wilayah Kota Bandung, baik sarana maupun prasarananya agar sesuai dengan standar nasional.

Kedua: Pemerintah Kota Bandung harus mengubah kebijakan kuota bagi tiap kelompok/golongan agar tidak menimbulkan kecemburuan sosial dan menutup peluang untuk praktek jual-beli kursi, yang selama ini selalu menjadi sumber pemicu konflik.

\section{DAFTAR PUSTAKA}

\section{Buku}

Anderson, J. E. 1979. Public Policy Making: An Introductin. Boston: Houghton Miffin Company. 
Baedhowi. 2009. Kebijakan Otonomi Daerah Bidang Pendidikan: Konsep Dasar dan Implementasi. Semarang: Pelita Insani.

Creswell, John W. 1994. Research Design: Qualitative \& Quantitative Approaches. California: Sage Publication.

Dunn, William N. 1994. Public Policy Analysis: An Introduction, New Jersey: Prentice-Hall Inc.

Dwidjowijoto, Riant Nugroho. 2004. Kebijakan Publik, Formulasi, Implementasi, dan Evaluasi. Jakarta: Gramedia.

Grindle, Merilee. 1980. "Polities and Policy Implementation in the Third World. New Jersey: Princestown Univercity Press.

Indiahono, Dwiyanto. 2009. Kebijakan Publik Berbasis Dynamic Policy Analysis. Yogyakarta: Gava Media

Islamy, Irfan. 2002. Prinsip-Prinsip Perumusan Kebijakan Negara. Jakarta: Bumi Aksara.

Jones, Charles 0. 1984. An Introduction to the Study of Public Policy. MontereyCalifornia: Brooks/Cole Publishing Company.

Lane, E. J. 1993. The Public Sector: Concepts, Models, and Approaches, London: Sage Publication.

Lilik Ekowati, Mas Roro. 2004. Perencanaan, Implementasi dan Evaluasi Kebijakan atau Program. Surakarta: Pustaka Cakra.

Mazmanian, D. A. \& Paul. A. Sabatier. 1983. Implementation and Public Policy. London: Scott, Forestnan and Company.

Meter, Donald Van dan Carl Van Horn. 1975. "The Policy Implementation Process, A Conceptual Frame Work". Administration and Society 6, 1975. London: Sage Publication.

Nugroho. D. Riant. 2009. Kebijakan Publik Formulasi, Implementasi dan Evaluasi. Jakarta: PT. Elex Media Komputindo Kelompk Gramedia.

Pressman, Jeffrey L and Wildavsky Aaron. 1978. "Implementation", dalam
Shafritz, Jay $\mathrm{M}$ and Hyde, Albert $\mathrm{C}$. Classic of Public Administration. Callifornia: Brooks/Cole Publishing Company.

Purwanto, E. Agus dan Sulistyastuti, D. Ratih. 2012. Implementasi Kebijakan Publik: Konsep dan Aplikasinya di Indonesia. Yogyakarta: Penerbit Gava Media

Sabatier, Paul A. 1993. "Top-Down and Bottom-Up Approaches to Implementation Research", dalam Hill Micheal. The Policy Process: A Reader. Halm 266-293. Hertfordshire. Haruester Wheatsheaf.

Supranto, J. 2004. Analisis Multivariat. Jakarta: Penerbit Rineka Cipta.

Wahab, Solichin Abdul. 2002. Analisis Kebijaksanaan dan Formulasi Implementasi Kebijaksanaan Negara. Jakarta: Penerbit Bumi Aksara.

Wibawa, Samudra. Yuyun Purbokusumo. Agus Pramusinto. 1994. Evaluasi Kebijakan Publik. Jakarta: Raja Grafindo Persada.

Winarno, Budi. 2002. Prosedur dan Proses Kebijakan Publik. Yogyakarta: Media Pressindo.

\section{Jurnal}

Ardhi, Mohammad. 2015. "Evaluasi Manajemen Penerimaan Peserta Didik Baru Sistem Real Time Online Dinas Pendidikan Kota Yogyakarta".

Becker, Rosa. 2012. "International Student Recruitment:Policies and Developments in Selected Countries".

Borchert, Michael. 2002. "Career Choice Factors of High School Students".

Dadson, Richard L. 2015. "An Analysis of The Relationship Between State Education Quality and Principal Preparation Practices".

Fitz, John. 2015. "Implementation Research and Education Policy: Practice and Prospects".

Flannery, K. Brigid. 2016. "Implementation of SWPBIS in High School”. 
Fumasoli, Tatiana. 2013. "Organizational Studies in Higher Education: A Reflection on Historical Theme and Prospective Trends".

Levy, Daniel C. 2013. "The Decline of Private Higher Education".

Lin, Shufang, etc. 2016. "An Empirical Study of Institutional Research in A Senior High School".

Locke, William. 2009. "Evidence Based Policy In Practice In National and Intrnational Contexts".

Marbun. H. E. B. 2014. "Kebijakan Penerimaan Peserta Didik Untuk Golongan Keluarga Miskin (GAKIN) Di Sekolah Menengah Pertama Negeri 5 Balikpapan".

Moja, Teboho. 2000. "Nigeria Education Sector Analysis: An Aanlytical Syntesis of Performance and Main Issues".

Mowen, Thomas J. 2014. "Punishment in School: The Role of School Security Measures".

Mulford, Bill. 2003. "School Leaders: Challenging Rolesand Impact on Teacher and School Effectiveness".

Matland. E. Richard. 1995. "Synthesizing the Implementation Literature: The Ambiguity-Conflict Model of Policy Implementation", Journal of Public Administration Research and Theory: J-PART, Vol. 5, No. 2 (Apr.,1995), pp. 145-174.

Stavrou, Sophia. 2016. "Pedagogising in University: On Higher Education Policy Implementation and its Effects on Social Relations".

Sopianto Basofi. 2015. "Implementasi Kebijakan Penerimaan Peserta Didik Baru (PPDB) Online Tingkat Sekolah Menengah Atas Di Kota Pekanbaru Tahun 2011-2013".

Stephan, Sharon. 2014. "School Mental Health: The Impact of State and Local Cpacity Building Training".
Tansel, Aysit. 2013. "Supplementary Education in Turkey: Recent Developments and Future Prospects".

Kuo, Yu-Ying. 2012 “Taiwan's Public Policy Education: US-Style".

Wang, Zhenmin. 2007. "Key Factors That Influence Recruiting Young Chinese Student".

\section{Disertasi}

Purwanti, Dian. 2019. Pengaruh Kebijakan Pemerintah terhadap Pelaksanaan Penerimaan Peserta Didik Baru, Perbandingan Pelaksanaan PPDB SMP Tahun 2017 dan 2018 di Bawah Peraturan Walikota Bandung Nomor 553 Tahun 2017 dan Nomor 456 Tahun 2018. Bandung: Pascasarjana FISIP Universitas Padjadjaran.

\section{Peraturan}

Peraturan Pemerintah Republik Indonesia Nomor 17 Tahun 2010 tentang Pengelolaan Penyelenggaraan Pendidikan.

Peraturan Menteri Pendidikan dan Kebudayaan Republik Indonesia Nomor 17 Tahun 2017 tentang Penerimaan Peserta Didik Baru.

Peraturan Menteri Pendidikan dan Kebudayaan Republik Indonesia tentang Penerimaan Peserta Didik Baru Sistem Zonasi.

Peraturan Walikota Bandung Nomor 610 Tahun 2016 tentang Petunjuk Teknis Pelaksanaan Penerimaan Peserta Didik Baru Di Kota Bandung.

Peraturan Walikota Bandung Nomor 553 Tahun 2017 tentang Petunjuk Teknis Pelaksanaan Penerimaan Peserta Didik Baru di Kota Bandung.

Peraturan Walikota Bandung Nomor 456 Tahun 2018 tentang Petunjuk Teknis Pelaksanaan Penerimaan Peserta Didik Baru di Kota Bandung. 


\section{TENTANG PENULIS}

${ }^{1}$ Dian Purwanti, S.Sos, M.AP adalah dosen Universitas Muhammadiyah Sukabumi, yang sedang menempuh Program Doktor di Pascasarjana FISIP Universitas Padjajaran.

${ }^{2}$ Dr. Dra. Hj. Ira Irawati, M.Si adalah dosen Program Pascasarjana FISIP Universitas Padjadjaran Bandung yang merupakan Promotor dari penulis ${ }^{1}$.

${ }^{3}$ Prof. Dr. Drs. H. Jossy Adiwisastra, M.S adalah dosen Program Pascasarjana FISIP Universitas Padjadjaran Bandung yang merupakan Promotor dari pemulis ${ }^{1}$.

${ }^{4}$ Dr. Drs. Herijanto Bekti, M.Si adalah dosen Program Pascasarjana FISIP Universitas Padjadjaran Bandung yang merupakan Promotor dari penulis ${ }^{1}$. 